\title{
Pesquisa Participativa e Julgamento dos Interlocutores: uma reflexão a partir de pesquisas em Antropologia Visual ${ }^{1}$
}

\section{Paulo Renato Guérios}

Universidade Federal do Paraná (UFPR), PR, Brasil E-mail:pguerios@ig.com.br 


\section{Resumo}

As pesquisas participativas ou compartilhadas tornaram-se uma referência metodológica na disciplina da Antropologia ao longo das últimas décadas, em parte como resultado à crítica dos fundamentos coloniais da Antropologia clássica. No entanto, corre-se o risco de equacionar diretamente a pesquisa participativa com a aceitação de seus resultados por parte dos interlocutores em campo. Com base em pesquisas realizadas no âmbito do curso de Ciências Sociais da UFPR, o presente artigo procura questionar até que ponto os julgamentos positivos ou negativos dos interlocutores aos produtos finais de uma pesquisa estão ligados à relação social que lhes dá origem. Argumenta-se que outros fatores, dentre os quais a consonância de objetivos e interesses entre pesquisadores e interlocutores ou a construção dos problemas de pesquisa podem ter também grande relevância na determinação do resultado desses julgamentos.

Palavras-chave: Antropologia Compartilhada. Pesquisa Participativa. Antropologia Visual.

\section{Abstract}

Participatory or shared research became a methodological reference in the discipline of anthropology over the past decades, partly as a result of criticism on the colonial foundations of classical anthropology. However, this approach should not be immediately associated to a positive assessment of the results of research by the groups in which it is conducted. Based on research carried out within the undergraduate course of Social Sciences at UFPR, this article questions the extent to which positive or negative assessments to their end products are linked to the social relationship through which they are construed. It is argued that other factors, such as consonance of goals and interests between researchers and their interlocutors or the construction of research problems may also have great significance in determining the outcome of these judgements.

Keywords: Shared Anthropology. Participatory Research. Visual Anthropology. 


\section{Introdução}

Wo final da década de 1960, após registrar uma série de rituais 1 entre os Dogon e de danças de possessão no Níger, Jean Rouch adaptou um equipamento para mostrar suas filmagens para os participantes destas manifestações. Ao estudar este material junto com seus informantes, conseguiu, segundo afirmou mais tarde, "[...] reunir mais informação em duas semanas do que havia conseguido em três meses de observações diretas e entrevistas" (Rouch, 2003a, p. 44). Sua conclusão, expressa em um trecho bastante citado, foi de que esse tipo de trabalho poderia inaugurar uma era de uma "antropologia compartilhada", em que uma nova relação seria estabelecida entre pesquisadores e pesquisados: o julgamento do trabalho do antropólogo seria feito "[...] não mais por comitês de teses, mas pelas próprias pessoas que o antropólogo saiu para observar" (Rouch, 2003a, p. 44). Esse julgamento permitiria também uma crítica ao olhar antropológico sobre um dado grupo feita pelo próprio grupo: nas palavras de Rouch, os filmes etnográficos constituem "[...] um meio que permite o diálogo e a discordância cruzando linhas sociais". (Rouch; Taylor, 2003, p. 137)

Os insights de Rouch foram desenvolvimentos precoces de temas que vieram a ocupar um papel proeminente na construção do conhecimento antropológico nas décadas seguintes. A possibilidade de um retorno crítico acerca da produção antropológica feita pelo próprio "nativo" marca uma ruptura com os fundamentos coloniais do discurso antropológico clássico, estruturado sobre uma relação desigual entre observador e observado e sobre a distância entre ambos, como observou Asad ( 1973) em seu texto clássico sobre o assunto. O nativo, transformado em interlocutor, é assim reconhecido como pertencente 
à mesma dimensão temporal do antropólogo, tornando a prática de pesquisa um momento de confronto de ideias, e não mais de uma pura observação (Fabian, 1991, p. 204). A centralidade da relação entre pesquisador e pesquisado para a produção do conhecimento antropológico veio a tornar-se assim um questionamento metodológico central na disciplina, desdobrando-se em diferentes propostas analíticas e metodológicas - como aquela do esforço pós-hermenêutico originado pela crítica pós-moderna de Marcus e Fischer (1986) nos Estados Unidos; ou, no Brasil, para tomar dois exemplos paradigmáticos advindos da etnologia indígena brasileira, a proposta do estabelecimento de uma relação de horizontalidade epistemológica feita por Viveiros de Castro (2002) a partir das noções de "invenção da cultura" de Roy Wagner e de "antropologia simétrica" de Bruno Latour; e a proposta de uma construção de conhecimento articulada às necessidades e demandas políticas concretas dos grupos pesquisados, ver, por exemplo, Pacheco de Oliveira (2013).

De fato, a multiplicação recente dos meios de acesso à informação e dos meios de comunicação, assim como a realização de pesquisas em contextos locais e com interlocutores próximos, tornaram muito mais comum o contato dos pesquisados com o resultado final das pesquisas feitas por antropólogos. No caso da produção de filmes etnográficos, o caráter aparentemente imediato do suporte audiovisual permite um trânsito ainda mais direto entre as concepções do antropólogo e aquelas de seu interlocutor em campo. O suporte fílmico facilita a superação não apenas da distância física ou de uma distância temporal imaginada entre pesquisador e pesquisado, mas principalmente da distância comunicacional: talvez nem todos os pesquisados tenham os recursos necessários ou se disponham a enfrentar a leitura de uma monografia, ${ }^{2}$ mas um filme etnográfico envolve a possibilidade direta de acesso ao processo de criação e ao produto final da pesquisa antropológica. A Antropologia Visual constitui assim uma subárea privilegiada na construção de uma reflexão acerca das dinâmicas compartilhadas de pesquisa e dos dilemas metodológicos implicados pela incorporação da relação entre pesquisador e pesquisado no âmbito de uma pesquisa etnográfica. 
Novas práticas de investigação, no entanto, exigem um esforço adicional no sentido de problematizar o alcance de seus pressupostos, das consequências epistemológicas das metodologias empregadas e dos limites das possibilidades de conhecimento que elas instauram. De fato, apesar de a relevância heurística da busca de uma construção compartilhada da pesquisa estar consolidada na antropologia contemporânea, corre-se o risco de, ao afirmá-la, estabelecer-se uma relação direta entre as dinâmicas da relação entre o pesquisador e seu interlocutor e o julgamento do produto final da pesquisa. Não necessariamente pesquisas compartilhadas resultam em julgamentos favoráveis de seus produtos, dado que a autoria final é compartilhada e negociada - e não exclusiva do interlocutor. Adicionalmente, outros elementos podem desempenhar um papel relevante na resposta dos interlocutores, por exemplo as características do tema ou objeto de pesquisa, a elaboração do problema a ser resolvido por ela, ou ainda os embates políticos acerca da definição de seu produto final. Por fim, pesquisas participativas ou compartilhadas podem ocorrer em diferentes registros, franqueando por exemplo o acesso aos interlocutores a resultados parciais da pesquisa, o que transforma o processo de construção de conhecimento em uma situação de confronto contínuo de ideias, ao invés de uma situação de restituição restrita à apresentação de seu produto final.

O presente artigo tem o objetivo de investigar comparativamente os resultados de pesquisas que utilizaram recursos audiovisuais, explorando as ligações entre as metodologias empregadas, as relações instauradas entre os pesquisados e seus interlocutores e as reações destes interlocutores aos processos e aos produtos finais das pesquisas. Trata-se assim de emprestar estatuto epistemológico aos momentos de restituição dos resultados de pesquisa aos grupos pesquisados, apostando, como o fez Nicolas Flamant (2005, p. 143) na fecundidade

[...] de analisar como os atores percebem estas situações [de recepção das informações restituídas], de identificar o que está em jogo para eles e as consequências que elas podem ter a seus olhos e de compreender o tipo de relações que estes atores constroem explicitamente ou implicitamente frente ao antropólogo nestes momentos de restituição. 
As etnografias aqui abordadas foram produzidas por estudantes do curso de Ciências Sociais da UFPR, no quadro de uma disciplina chamada Práticas de Filmes Etnográficos. Esta disciplina é parte de um esforço de inserir a reflexão acerca do uso de recursos audiovisuais na pesquisa antropológica na formação dos alunos do curso. Foram oferecidas aos estudantes duas disciplinas nos últimos anos, sendo que a primeira promoveu uma revisão das principais metodologias utilizadas por autores reconhecidos na produção de filmes etnográficos, ${ }^{3}$ e que a segunda, a disciplina prática citada acima, propôs que os alunos fizessem seus próprios filmes sobre temas à sua escolha ${ }^{4}$. Os alunos que participaram desta segunda disciplina estavam em geral entre o quarto e o sexto períodos de Ciências Sociais e já haviam, assim, cursado boa parte das disciplinas teóricas e metodológicas do curso - mesmo os alunos de quarto período já haviam tido uma experiência de trabalho de campo na disciplina de Antropologia e Práticas Etnográficas. Desse modo, a disciplina de Práticas de Filmes Etnográficos constou: de duas aulas introdutórias acerca da construção de problemas de pesquisa em Antropologia Visual; de três aulas acerca de técnicas de captação de imagem, de som e de edição; de seis aulas de discussões acerca das diferentes possibilidades de relação entre o pesquisador e seu interlocutor ao longo de uma pesquisa fílmica (filmes expositivos, observacionais e compartilhados); de quatro aulas de discussão coletiva dos projetos de pesquisa de cada equipe; e, ao longo dos dois meses seguintes, de encontros para a discussão do progresso de cada pesquisa. Como resultado, foram produzidos pelos alunos 12 filmes com duração entre 20 e 40 minutos.

Pretende-se aqui estabelecer uma análise comparativa do processo de produção e das reações, por parte dos grupos filmados, a alguns destes filmes - aqueles que tiveram um rendimento maior para esta discussão. Utilizando como material empírico os filmes apresentados, os projetos elaborados pelas diferentes equipes, os relatos acerca do desenvolvimento dos projetos, os relatórios finais das equipes e as manifestações dos grupos filmados quando da projeção dos filmes - seja relatadas pelos alunos, seja observadas em sala no caso dos grupos convidados a participar das projeções feitas ao final da disciplina - 
busca-se compreender como tais reações podem ou não estar ligadas: à relação estabelecida entre pesquisador e pesquisado em cada caso; à concepção do objeto e do problema de pesquisa por parte das partes envolvidas no processo; ou à consonância de objetivos e interesses entre eles. Trata-se aqui assim de, partindo de eventos concretos, refletir sobre as possíveis interfaces entre a relação social envolvida em cada pesquisa, os embates entre diferentes olhares e a produção de conhecimento no quadro de pesquisas antropológicas compartilhadas.

Para proceder a esta discussão, a apresentação dos filmes realizados será dividida em dois blocos, de acordo com os objetos que eles se propuseram a enfocar: primeiramente, os filmes acerca de grupos de performance artística; a seguir, os grupos envolvidos em mobilizações de caráter político ou militante.

\section{Etnografias de Grupos de Performance: a questão da representação}

Conforme colocado acima, a disciplina oferecida aos alunos do curso de Ciências Sociais da UFPR propunha que cada equipe realizasse um filme etnográfico cuja escolha do tema e do problema de pesquisa seriam da própria equipe. Como resultado, houve uma divisão temática nos produtos finais das pesquisas entre etnografias de grupos de performance artística (música, dança e teatro) e etnografias de grupos militantes ou políticos (recicladores de lixo, movimento negro, relações livres não monogâmicas). Essa diferença nos objetos de pesquisa implicou em uma clara diferença na definição das relações estabelecidas entre os pesquisadores e os grupos, na delimitação dos problemas e nas reações dos grupos filmados aos produtos finais da pesquisa. Neste item, serão discutidos os resultados relativos às produções acerca de grupos de performance.

O primeiro filme a ser abordado tratou de um grupo de música celta radicado em Curitiba. Uma das componentes da equipe de pesquisa conhecia o trabalho do grupo e contatou-o através da rede social Facebook. Segundo o relatório da equipe,

G. explicou brevemente que somos estudantes de Ciências Sociais da UFPR, a proposta desta matéria [de 
produção de filmes], o motivo da escolha da banda e o que pretendíamos filmar. Ainda neste texto, citou ter frequentado alguns shows e acompanhado as atividades da banda por meio das redes sociais. Recebemos uma resposta no mesmo dia da página da banda. [...] Um dos membros escreveu que a banda julgou a iniciativa fantástica e passou seu número de celular para que pudéssemos contatá-lo. [...] dias depois recebemos uma mensagem dele, dizendo que havia conversado com a banda e que eles decidiram marcar uma reunião conosco para entender melhor o que pretendíamos.

Este primeiro trabalho foi assim realizado com um grupo musical com o qual a equipe de pesquisa não tinha contato prévio. Dentro do próprio grupo, havia divergências acerca da conveniência da produção do filme. O membro da banda que fez o primeiro contato teve uma resposta entusiástica no início, mostrando-se "extremamente disposto a conversar sobre si, sua música, a cultura celta e o nosso projeto", segundo a equipe, mas parecendo "não estar tão aberto nos outros momentos em que gravamos". Um segundo membro "por sua vez parecia encarar a câmera cada vez com mais tranquilidade, e os demais músicos também estabeleceram uma boa relação conosco". Um novo integrante da banda não pôde estar presente na primeira reunião e foi convidado para uma entrevista em separado, ocasião em que apresentou discursos e posições acerca da música tradicional diferentes daquelas expressas pelo resto da banda. A presença da equipe de pesquisa trouxe assim à tona divergências internas ao grupo.

Em seu projeto apresentado no início das filmagens, a equipe propôs desenvolver um estudo acerca das relações sociais construídas em torno da música celta pelos membros da banda. Já na primeira entrevista, no entanto, ao conversar com o grupo, a equipe percebeu “que eles falavam muito mais do que estudavam, como aspectos históricos dos celtas, do que da constituição e funcionamento da banda. A partir de então, decidiu-se que se tentaria trabalhar a relação da banda com a tradição". Nesta mesma reunião, a equipe explicou à banda que "[...] o trabalho etnográfico se constrói no decorrer da pesquisa, portanto nós iríamos percebendo aos poucos as questões que nos interessavam [...]"; propôs que o filme seria feito de acordo com esta compreensão 
da etnografia, e que "[...] em troca cederíamos todo o material que tivéssemos para que a banda usasse como bem entendesse $[\ldots]$ ", o que a banda considerou "uma boa troca".

Ao mesmo tempo em que a equipe de pesquisa decidia o tema que iria desenvolver no filme a partir das conversas com a banda, no entanto, dentro da própria banda ocorria outra dinâmica. O membro do grupo que fizera o contato inicial pediu que a partir de então as gravações fossem planejadas com as suas "assessoras", esposas de dois dos membros. No final da gravação de um show, uma delas disse à equipe, segundo consta do relatório final, que “[...] já sabia como nós poderíamos dar sequência ao filme, onde ficaria mais bonito gravar e como deveríamos começar o filme". A equipe, percebendo que a assessora pensava em dirigir seus trabalhos no sentido da produção de um documentário com a estética dos videoclipes, respondeu que tinha sido acertado que o material filmado seria entregue à banda para que o usasse como achasse melhor, ao que a assessora respondeu que “[... havia decidido que usaria o filme que faríamos para a disciplina, o que seria mais prático". No entanto, segundo a equipe, "[...] ao conversar com os músicos em outros momentos percebemos uma visão bastante diferente: eles estavam de acordo com a nossa proposta, não estavam sabendo desta situação com a assessora". A equipe passou a manter contato mais próximo com a segunda assessora, e a primeira, "talvez notando nosso receio e desconforto acerca daquela conversa, não tocou mais no tema de modo tão direto".

As filmagens prosseguiram então de acordo com o projeto da equipe, que filmou outros shows, fez entrevistas com fãs da banda e editou o material no sentido de restituir o modo pelo qual a banda se relacionava com a cultura celta.

Após o final da disciplina, surgiu a oportunidade de veicular alguns dos filmes produzidos pelos alunos na TV UFPR. Várias equipes tinham já obtido autorização dos grupos filmados para veiculação das imagens, mas este não era o caso desta equipe. A banda foi então contatada, e a assessora encaminhou uma mensagem em que o líder do grupo solicitava que o vídeo não fosse divulgado antes que fossem corrigidas a captação de som, os cortes abruptos da edição e a sincronia 
do áudio em alguns momentos, que o faziam parecer "amador". Em uma mensagem enviada diretamente à equipe de pesquisa, o mesmo membro da banda agradecia pelo trabalho de pesquisa e solicitava apenas o envio do mesmo filme com as questões técnicas apontadas corrigidas, para que ele pudesse ser divulgado.

Essa experiência permite-nos iniciar a reflexão acerca das interfaces entre a situação de pesquisa, o modo de produção de conhecimento envolvido e o julgamento do produto da pesquisa por parte dos grupos pesquisados. Fica claro que a equipe não optou por dar acesso, ao grupo filmado, à definição acerca dos rumos que a pesquisa - e o filme - tomariam. Não houve assim um esforço na construção de uma antropologia compartilhada, em que o produto final fosse a resultante de negociações entre o pesquisador e seus interlocutores: foi a própria equipe de pesquisa que, informada por suas leituras teóricas e metodológicas, delimitou a mudança no problema de pesquisa, a estética a ser utilizada e a edição que resultou no filme sobre a banda.

Foi assim estabelecida uma situação de pesquisa que tinha potencial de gerar um conflito de expectativas: apesar de a equipe de pesquisa explicitar desde o início a dinâmica que seria seguida na pesquisa e obter o acordo da banda a este respeito, ficou claro posteriormente que, para a primeira assessora, tratava-se de uma oportunidade de divulgação da banda, e que havia a expectativa do emprego de uma linguagem comercial pré-definida nas filmagens; já o líder do grupo mostrou-se satisfeito com o conteúdo do filme, mas esperava um grau de excelência técnica conforme à imagem de "profissionalismo" que tinha da banda.

Um primeiro ponto a ser destacado, assim, é que neste caso a filmagem parecia interessante para a banda por constituir a oportunidade de servir como divulgação de seu trabalho - e que, para que esta expectativa fosse cumprida, a pesquisa deveria seguir uma lógica comercial de apresentação de um produto nos moldes da indústria cultural contemporânea. Esse interesse escapava ao enquadramento que a equipe pretendia emprestar a sua pesquisa. Foi assim gerada uma distância entre as expectativas da equipe de pesquisa e aquelas do grupo pesquisado. 
Nas filmagens de grupos de performance, a preocupação com a veiculação de uma imagem do grupo e a compreensão de que um filme etnográfico pode servir como material de divulgação e propaganda esteve envolvida em todos os $\operatorname{casos}^{5}$. Em um segundo projeto, realizado com uma banda de música islandesa tradicional, apenas um dos integrantes do grupo musical estava convencido da validade da produção do filme, segundo o relatório da equipe. Conversando pessoalmente com outro dos integrantes, perguntei-lhe o que ele tinha achado da sua participação no projeto, ao que ele respondeu:

A filmagem foi feita no início da banda, acabou não passando o que a gente gostaria de passar dela. Hoje temos um repertório muito maior, já tocamos em bares. Não fui contra o filme, mas achei precoce fazer um documentário sobre uma banda que ainda não existia direito. Era muito marketing para pouca música.

A mesma questão surgiu em outro dos trabalhos realizados com grupos de performance, resolvida no entanto de forma oposta. No trabalho, acerca de um grupo de danças orientais, a equipe de pesquisa realizou um retrato entusiasmado da arte da coordenadora do grupo. Após a projeção do filme, os comentários da plateia - composta por alunos, sujeitos filmados e dois professores do Departamento de Antropologia da UFPR - questionaram o grupo acerca dos limites entre um filme etnográfico e uma peça de propaganda de um grupo artístico. Neste caso, não houve uma antropologia compartilhada pelo motivo oposto: se no primeiro caso a equipe de pesquisa monopolizou a organização do material empírico, neste o filme tornou-se quase uma autorrepresentação congratulatória da coordenadora do grupo de dança, apagando não tanto a participação do interlocutor quanto a própria voz do etnógrafo.

Nesses casos, em que havia um interesse de divulgação por parte do grupo filmado, seria necessária uma convivência mais longa e a possibilidade de estabelecimento de um vínculo dialógico mais profundo para que o produto final da pesquisa contemplasse de fato o confronto entre o olhar da equipe de pesquisa e aquele de seus interlocutores em campo - algo que deveria ser negociado paulatinamente 
entre as partes. No entanto, mesmo com o estabelecimento de uma forma compartilhada de pesquisa e de uma relação mais intensa, não necessariamente a relação de pesquisa resultaria em um tal confronto de olhares. Foi o que ocorreu com um outro filme, produzido acerca de um grupo de teatro de intervenção urbana.

No caso deste filme, como consta do projeto apresentado no quadro da disciplina, desde o início a equipe da pesquisa fez uma “[...] opção por seguir uma metodologia compartilhada na produção do etnodocumentário ${ }^{6}$, [o que] vincula-se a uma estratégia de pesquisa afinada com as dinâmicas do grupo que pretendemos retratar". O objetivo do projeto seria "[...] desvendar e demonstrar como é o processo de produção coletiva das intervenções urbanas neste momento do grupo". As intervenções urbanas, por sua parte, foram compreendidas como "práticas artísticas que, por meio das artes visuais, dança, teatro ou música interrompem o cotidiano da cidade com elementos distintos ao de sua lógica, provocando e alterando o imaginário dos transeuntes".

O grupo performático estava funcionando a partir da produção de cadernos individuais. Cada membro do grupo propunha por escrito as intervenções que faria, e os cadernos circulavam entre os demais, que intervinham por sua vez nos cadernos dos colegas. A equipe de pesquisa buscou "entrar na lógica dos cadernos com a ideia do documentário, tendo um caderno que representa a equipe para que eles também pudessem colaborar para a produção e criação do filme". Tratava-se então, para a equipe, de produzir uma "intervenção etnográfica, ocupando um lugar assim que não é nem dentro nem fora, intervindo nas dinâmicas de produção do grupo ao mesmo tempo em que construímos nosso filme incorporando as sugestões dos interventores". Ao longo do desenvolvimento da pesquisa, a equipe forneceu uma segunda câmera aos membros do grupo, incorporando imagens nas quais eles próprios apareciam; os membros do grupo de intervenção sugeriram cenas, e participaram conjuntamente da montagem de trechos do filme final.

Todo o processo foi assim calcado em uma construção compartilhada e participativa da pesquisa. De fato, mesmo a lógica da produção da pesquisa seguiu a lógica dos interlocutores, adotando sua compreensão do que eram as intervenções e permitindo-se ser objeto 
das intervenções do grupo. De modo análogo ao que Jean Rouch (2003b) denominou de ciné-transe, a teoria do grupo pesquisado (no caso de Rouch, a possessão Songhay, no caso deste grupo, a lógica das intervenções) foi empregada como parâmetro para a compreensão do papel e da forma de atuação do pesquisador.

Uma tal situação poderia gerar a expectativa de uma resposta positiva ao produto final da pesquisa. No entanto, o julgamento do grupo de teatro ao filme final foi ambíguo. De fato, apesar de a ideia fundamental da pesquisa constituir-se em uma série de intervenções recíprocas entre a equipe de pesquisa e o grupo teatral, gerou-se uma expectativa de obter, ao final do processo, um filme representativo do que era o grupo. Após apresentar a edição final ao grupo performático, uma das participantes da equipe de pesquisa relatou que

[...] a reação dos participantes ao ver o documentário me deixou intrigada, percebia uma sensação de estranhamento vindo por parte deles. Não sei quais eram suas expectativas anteriores ao vê-lo, mas por suas reações e comentários senti como se não gostassem do resultado final. G. diz não se identificar com o filme, que as intervenções urbanas não estavam presentes nele e que talvez não fique claro para quem não conhece o grupo quais são suas atividades. D. sente a necessidade de dar continuidade ao filme, me fazendo refletir se para ele, o filme estaria incompleto.

Depois que eu explico a proposta do filme, de que seu objetivo não era retratar fielmente o grupo, mas sim seu processo de criação e a relação do grupo com a câmera, e depois de D. escutar duas ou três vezes o trecho em que aparece esse objetivo no filme, a conversa começa a fluir. Surgem comentários falando sobre a não neutralidade do grupo da UFPR, quando nós aparecemos no filme, dessa forma mostrando que eu também estou dentro do grupo, ou quando D. fala que o filme não é o grupo, mas um olhar feito sobre ele.

Algo similar ocorreu com todos os projetos descritos até aqui inclusive com este último, o único dentre eles que se propôs a utilizar uma estratégia compartilhada em sua produção: gerou-se, ao longo do processo, a expectativa de que o produto final constituiria um retrato 
fiel dos grupos filmados. Isso ocorreu, como vimos, mesmo nos casos em que esta representação não era o objetivo consciente do projeto por parte das equipes de pesquisa - que ora deixavam em aberto qual seria o eixo a ser seguido na produção do filme, ora definiam questões específicas, acabando no entanto por operar, na prática, com a ideia de produzir uma tal representação.

Tal situação configurou, em todos os casos, uma grande armadilha. Por um lado, a busca por uma representação fiel da essência de um indivíduo ou grupo envolve necessariamente uma (auto)ilusão ou engano, uma expectativa de que tal imagem apenas poderia ser positiva. Como afirmam Barbash e Taylor (1997, p. 54), “[...] suponha que você embarque em um filme com promessas de retratar seus sujeitos honestamente. Eles muito provavelmente presumirão que isso significa que você os filmará sob uma luz relativamente lisonjeira". Por outro lado, mesmo que desejando fazê-lo, as equipes de pesquisa não conseguiriam restituir a autoimagem de cada grupo, pois, de fato, as próprias autorrepresentações internas de um dado grupo jamais serão homogêneas. Como argumentou Magnani (1986), ao efetuar uma releitura dos Baloma de Malinowski, há diferenças entre uma crença compartilhada por um grupo, as especulações individuais de cada um de seus membros e as práticas efetivas de todos eles - e cada um destes elementos se relaciona com o outro de maneiras complexas. A partir do momento em que o objetivo do filme, na concepção das partes envolvidas, passou a envolver a expectativa da produção de uma imagem representativa de quem era filmado, o seu resultado final estava destinado a gerar uma insatisfação por parte dos grupos pesquisados ou dos interlocutores em campo.

Ao mesmo tempo, contudo, isso não significa que pesquisas com grupos de performance necessariamente resultem na construção de uma tal expectativa. Dentre os filmes produzidos nesta rubrica, apenas um, feito junto a uma banda de música pop, teve uma resposta completamente positiva por parte dos interlocutores. Nesse caso, a equipe deixou claro desde o início que seu problema de pesquisa não tinha como foco criar uma representação do grupo, mas sim acompanhar o processo de composição de uma música por parte dele - e manteve tal 
questão em mente ao longo de todo o processo. Tratava-se aí, como afirmado no projeto da equipe, de definir como objeto da pesquisa

[...] um processo em que temos um estágio inicial de composição, levado adiante através do diálogo com os membros da banda, até chegar a sua conclusão. [...] Colocando de forma clara, a pergunta que levantamos é a seguinte: como ocorre o processo criativo por trás de uma música, desde o momento em que surgem as primeiras ideias na cabeça do músico, até sua execução enquanto produto acabado?

A consecução do projeto foi facilitada pela existência de uma relação prévia de amizade entre um dos membros da equipe da pesquisa e os componentes do grupo musical. De fato, eles já haviam pensado juntos em produzir um filme acerca desta questão alguns anos antes e contavam inclusive com tomadas feitas acerca do assunto em outras ocasiões. Havia assim, neste caso, um consenso bastante estabelecido entre as partes acerca dos objetivos do projeto, o que gerou um produto final que resultou de uma negociação longa e efetiva entre os lados envolvidos. O acordo obtido ao redor do filme finalizado adveio então não apenas do estabelecimento de uma relação construída a partir de uma metodologia compartilhada, mas também de um consenso acerca do problema de pesquisa: apesar de o filme envolver a imagem da banda, seu objetivo não era realizar um retrato do grupo, mas sim refletir acerca de uma questão relativamente autônoma em relação a ele. A elaboração conjunta e a própria natureza do problema de pesquisa, não focado sobre a construção de uma imagem do grupo, foi assim fundamental para que o produto final tivesse um resultado tido como satisfatório por ambas as partes envolvidas.

\section{Etnografias de Grupos Militantes: engajamento e participação}

O segundo bloco de trabalhos produzidos pelos estudantes de Ciências Sociais da UFPR no quadro da disciplina de Prática de Filmes Etnográficos tinha como objetos os movimentos sociais de reivindicação política ou demandas de grupos minoritários. No caso destes 
trabalhos, como veremos, desde o princípio era claro para as equipes e seus interlocutores que ambos os lados partilhavam de certos pressupostos fundamentais acerca da temática das pesquisas.

O primeiro trabalho que se discute iniciou-se com a proposta de acompanhar as relações entre moradores que ocuparam um edifício abandonado em um bairro de classe média alta de Curitiba e seus vizinhos, representados por uma Associação de Moradores. Essa Associação vinha demandando ao poder público que providenciasse uma resolução para a ocupação do edifício, argumentando que ele era um foco de doenças por ter áreas com água parada, e relacionando a violência no bairro com a presença de seus ocupantes.

Uma das alunas da equipe de pesquisa já mantinha contato há mais de um ano com um casal que morava no prédio abandonado. No primeiro encontro relativo a esta pesquisa, ela iniciou a interação com os moradores com uma conversa que veio a constituir a primeira cena do corte final do filme:

- Mas agora o seguinte, P., a gente está fazendo um vídeo para a faculdade. A gente quer saber se a gente pode filmar.

- Pode filmar, pode.

- É sobre...

- Sobre...? sobre mandar lá pro Gilberto Ribeiro...

- Quem é o Gilberto Ribeiro?

- O Gilberto Ribeiro tá falando que tem uma campanha, que então, 50 carrinheiros, é pra ser beneficiado, os que já são cadastrados na Provopar, vão dar um benefício de 320 reais por mês, uma cesta básica, bolsa... de família, assim, e o Gilberto Ribeiro falou hoje dessa campanha que inventaram pela Provopar e pela Fiesp Paraná, que eles vão beneficiar esses carrinheiros, e daí eu queria entrar nesse benefício, M., e eu não tenho como entrar. Talvez o teu intermédio, você fazer um vídeo...

- Por que que você não consegue entrar?

- Porque eu não tenho um intermédio. Talvez você possa fazer esse intermédio pra mim e mandar um vídeo pra ele. Daí vai na TV, na Record, e entrega esse vídeo. E fala que eu sou um dos carrinheiros, e tô precisando de um benefício no meu carrinho, pra restaurar meu carrinho, 
mostrar meu carrinho com o cachorro dentro, como eu trabalho, e preciso mesmo de um carrinho um pouco melhor, talvez... vai ser um benefício pra mim, entende? Mandar um vídeo pra ele. O Gilberto Ribeiro, você entra no Facebook dele, que é gilbertoribeiro.com.br, lá, pra RIC $\mathrm{TV}$, que ele é um deputado aqui de Curitiba, que eu votei nele, é um dos melhores radialistas [...]

Já no primeiro contato relativo à produção do filme, assim, o interlocutor formulou uma demanda bastante clara à equipe de pesquisa: pedia que fosse feito um vídeo para envio a um programa de TV de uma emissora local, que intermediava a relação dos carrinheiros de Curitiba com um projeto social do Governo do Estado. Sem ter uma visão muito clara dos meandros envolvidos em sua demanda, o morador tinha no entanto total clareza acerca da oportunidade que a presença da equipe de pesquisa lhe proporcionava: a de poder contar com um "intermédio" para ter acesso aos "benefícios" que sabia estarem disponíveis.

Imediatamente, o objeto e o problema da pesquisa foram alterados pela equipe. Seus membros passaram a documentar todos os passos que seguiram para atender à demanda de seu interlocutor, acabando por retratar as relações mútuas entre seus interlocutores, a mídia televisiva e eles próprios. Constituíram assim a superfície final do filme: a produção do vídeo com P. para envio à TV; o contato e a vinda da equipe do programa de TV ao prédio; a filmagem que a equipe de TV fez com P. e sua esposa; a relação estabelecida entre a equipe de TV e a equipe de pesquisa; e, finalmente, o momento em que o casal de moradores assistiu a sua aparição no programa de TV. Ao longo de todo o processo, P. tinha clareza de que a implementação ou não do "benefício" não dependia da equipe de pesquisa, mas que esta servia a ele como uma intermediária na tentativa de obtê-lo - como afirmo ao longo das filmagens, em cena mantida no corte final.

O filme resultou então em um retrato dinâmico das relações estabelecidas entre as partes a partir de um acontecimento gerado pela própria presença da câmera dos pesquisadores. Em uma proposta também bastante alinhada àquela de Jean Rouch, a relação entre as partes envolvidas ao longo das filmagens não foi "[...] predicada no 
registro de uma realidade etnográfica objetiva. Ao contrário, as realidades etnográficas [foram] produzidas no e através do próprio encontro etnográfico" (Grimshaw, 2001, p. 98). O próprio Rouch referiu-se a essa abordagem como "intervir para provocar uma certa realidade" (Rouch; Taylor, 2003, p. 141): a participação de pesquisador e pesquisado ao longo da relação de pesquisa, assim, remete "[...] à capacidade de transformação e alteração a que estão submetidos os chamados nativos e pesquisadores numa relação entre sujeitos" (Gonçalves, 2008, p. 66), e não entre um pesquisador visto como sujeito e um observado tratado como objeto de estudo. No próprio filme, é possível perceber como os interlocutores em campo engajaram-se no processo de pesquisa e ficaram satisfeitos com seu resultado.

É interessante no entanto estabelecer uma comparação entre este filme e outros dois que se dedicaram a temas relativos à militância em duas áreas distintas: as relações amorosas livres e o movimento negro em Curitiba. Nestes casos, houve uma resposta positiva dos interlocutores em campo aos filmes finais, mesmo sem que houvesse um esforço na construção de um registro compartilhado de pesquisa ou de uma participação mais efetiva dos interlocutores na definição de seus rumos. É importante destacar que os pesquisadores, em ambos os casos, declararam-se simpatizantes dos movimentos que abordaram nas pesquisas.

No caso do primeiro filme, a equipe da pesquisa, já "familiarizada com o tema por interesse pessoal e compreendendo razoavelmente bem o panorama da não-monogamia", segundo consta de seu relatório, consultou a página da "Rede Relações Livres Brasil" para informar-se melhor sobre as ideias do grupo, e estabeleceu contato com a seção paranaense do movimento através da moderadora do grupo do Facebook "Rede Relações Livres Paraná". Através dessa pessoa, conseguiram agendar entrevistas com uma série de pessoas do movimento. O filme foi construído a partir de uma edição criteriosa, feita pela equipe sem a participação dos entrevistados, e construída a partir da organização dos trechos filmados segundo um critério temático.

Como a própria equipe de pesquisa tinha o objetivo de disponibilizar o filme na internet, buscou obter já ao longo do processo de 
produção autorizações dos seus interlocutores em campo para a divulgação de suas imagens. Combinou assim com todos que após eles assistirem à edição final seria feita a confirmação de seu aceite para esta divulgação. Como resultado, apenas uma das pessoas entrevistadas ficou em dúvida. Sua questão, no entanto, era, como no caso do filme dos cosplayers, ${ }^{7}$ de confidencialidade: segundo a equipe afirmou em seu relatório, ela

[...] dizia estar no "armário RLi", não era do conhecimento de várias pessoas de seu convívio que ela se considera nãomonogâmica. Mesmo assim, disse que se o filme ficasse legal ela concordaria em divulgá-lo, pois se sente num momento bom para "se assumir", e que tal exposição não teria problemas.

A segunda pesquisa abordou a trajetória e o trabalho de D., uma "cabeleireira afro e tranceira" curitibana, dona de um salão de beleza especializado em cabelos de mulheres negras e que "atua em oficinas sobre estética afrobrasileira e relações étnico-raciais voltadas para alunos, professores e gestores da educação básica". A equipe propôs, em seu projeto, acompanhar o cotidiano de D. para: "inquirir em que medida estas trajetórias e escolhas estéticas individuais [...] se aproximam de questões identitárias e étnico-raciais"; compreender "como referenciais estéticos podem colaborar na construção ou reconstrução das afirmações identitárias"; "repensar a dinâmica de uma cidade [Curitiba] que ainda se baseia em um ideal de população majoritariamente branca e de ascendência europeia"; e aliar-se às pesquisas "que buscam auxiliar nas reflexões de alternativas para reduzir o preconceito e a discriminação social". A equipe cita ainda um documentário sobre o mesmo assunto produzido por uma jornalista nigeriana que considera a "transição dos cabelos" (a interrupção do uso de cremes ou produtos de alisamento) "como um movimento de autoafirmação, sobretudo como um ato político".

Nesse caso, a equipe propôs desde o início construir o filme em conjunto com seus interlocutores, afirmando que pretendia "[...] respeitar as opiniões tanto dos idealizadores quanto dos sujeitos filmados". Na prática, contudo, a autoria do filme manteve-se fortemente 
em mãos da equipe de pesquisa: eles mostraram o projeto a D. e a seu marido (que acompanha os trabalhos do salão de D. de perto), assim como "[...] a edição bruta, para que pudessem opinar e sugerir alterações". No entanto, foi a própria equipe que tomou as decisões pertinentes às filmagens e à edição. Ao mesmo tempo, em seu relatório, os membros da equipe afirmam que foram “[...] sempre muito bem recebidos no salão de $\mathrm{D}$. e sentimos, em vários momentos, que as frequentadoras do lugar julgavam o que estávamos fazendo como algo extremamente importante".

Na mostra final dos filmes da disciplina, foi esta também a produção que atraiu mais público: além de D. e de seu marido, estiveram presentes estudantes e militantes do movimento negro de Curitiba. Ao final da sessão, o marido de D., que é professor de filosofia em escolas da rede pública da cidade, fez um balanço dos filmes que havia visto. A partir de minhas anotações, reproduzo aqui aproximadamente sua fala - valiosa para perceber o caráter imediato atribuído à produção fílmica:

Considero esses filmes fundamentais para criar aquilo que falo para meus alunos, que são as oportunidades de intersubjetivação. Os filmes apareceram como um instrumento político, que deixa a própria pessoa expor sua concepção de mundo. Fico feliz que a academia esteja abrindo espaço para isso. São canais para que você explicite o seu modo de perceber a realidade. Penso que vocês da Antropologia estão enraizados com a realidade. Vou precisar desse documento para mostrar o conhecimento da realidade para nossos alunos, para que eles tenham condições de compreender a questão do que é ser afro-brasileiro, ser brasileiro pelo viés africano.

Os três filmes discutidos nesta seção, mesmo tendo sido feitos com graus diversos de compartilhamento da pesquisa entre as partes envolvidas, tiveram assim grande aceitação por parte dos interlocutores em campo. Mais do que as relações envolvidas no processo de produção fílmica, eles têm em comum entre si o fato de terem sido produzidos a partir de um acordo acerca do significado político do que estava sendo filmado. 


\section{Considerações Finais}

No início do presente artigo, resgatamos o modo pelo qual Jean Rouch, de forma pioneira, estabeleceu uma ligação entre a proposta de uma antropologia compartilhada e o julgamento dos interlocutores em campo acerca das pesquisas antropológicas de que eles participam. Ao longo deste texto, buscou-se utilizar as experiências concretas de pesquisa dos alunos da disciplina de Práticas de Filme Etnográfico da UFPR para investigar o modo pelo qual as reações de seus interlocutores aos produtos finais das pesquisas poderiam estar relacionados ao modo pelo qual elas foram conduzidas.

Por um lado, foi possível perceber como, efetivamente, a criação de expectativas convergentes ao longo do próprio processo de pesquisa resultou em leituras mais favoráveis dos filmes por parte dos grupos pesquisados. As equipes que optaram por manter consigo a autoria e a edição dos filmes - como ocorreu no caso da pesquisa do grupo de música celta - tiveram respostas menos positivas a suas pesquisas, talvez justamente por suas visões não terem sido submetidas a um processo de confronto e de negociações ao longo dos quais diferentes olhares poderiam vir a assumir um consenso ou ao menos uma maior afinidade.

Ao mesmo tempo, contudo, nem todas as equipes que se dispuseram a fazer pesquisas compartilhadas tiveram respostas positivas. O filme acerca do grupo performático de teatro resultou, na visão do grupo, em uma representação falha acerca de suas atividades. Ao contrário, filmagens menos compartilhadas, como é o caso das entrevistas acerca das relações livres ou mesmo do projeto acerca dos cabelos afro, pareceram ter obtido respostas positivas por serem construídas a partir de concepções políticas compartilhadas acerca do objeto.

Ao mesmo tempo, deve-se considerar que diferentes pesquisas compartilhadas acabam por estabelecer diferentes tipos de vínculo entre os pesquisadores e seus interlocutores, como é visível na diferença entre a pesquisa do grupo performáticos de teatro e aquela do casal de carrinheiros. De fato, ao compartilhar o acesso à construção da pesquisa, o antropólogo se dispõe a realizá-la em um constante confronto 
com as demandas de seus sujeitos, o que gera embates e situações que divergem de acordo com as dinâmicas concretas estabelecidas ao longo do processo de pesquisa. Como afirma Flamant (2005, p. 143) a reação dos interlocutores de uma pesquisa a seus resultados “[...] não é desencarnada do espaço estudado e não ocorre assim desligada das lógicas sociais e simbólicas que anima este espaço [...]" - espaço do qual o antropólogo passa a fazer parte a partir do momento em que inicia sua pesquisa ${ }^{8}$.

Não há assim como estabelecer uma relação direta entre o julgamento dos interlocutores e o registro sob o qual é construída a relação de pesquisa. As respostas dos interlocutores acerca dos produtos finais da pesquisa parecem também estar relacionadas a outros fatores, tão relevantes quanto esta relação. Por um lado, a construção, ao longo do processo de pesquisa, de uma forte expectativa de constituição de uma representação do grupo pesquisado no filme gerou em alguns casos uma resposta negativa a ele. Representações de um grupo, conforme já se discutiu, são sempre objetos de controvérsia, seja dentro do próprio grupo ou, ainda mais, quando produzidas fora dele: como afirma Pacheco de Oliveira no caso das populações indígenas (2013, p. 64),

[...] o fato de que uma pessoa de fora, que possa escapar aos mecanismos locais de controle, seja posta em posição de autoridade, de algum modo julgando e interpretando questões que são objeto de discussão interna e reformulação entre eles, pode constituir-se em ameaça.

Por outro lado, também as características inerentes a dados objetos ou temas de pesquisa parecem assumir um papel importante na resposta dos interlocutores aos produtos das pesquisas antropológicas. Nos casos aqui examinados, grupos de performance constituíram-se como temas mais espinhosos do que grupos de militância política, pois suas próprias características enquanto objeto de pesquisa pareceram conduzir, mesmo que não de forma exclusiva, a uma ênfase maior na criação de uma imagem - o que parece ter gerado respostas menos positivas aos produtos finais das pesquisas.

Por fim, cabe questionar brevemente o significado da reação positiva aos filmes por parte dos grupos filmados. Por um lado, parece 
claro que a incorporação dos discursos ou valores dos interlocutores de uma pesquisa em sua própria lógica interna permite trazer à tona o fato de que a relação entre o pesquisador e seu interlocutor, seja qual for a metodologia empregada, fundamenta-se em uma relação social que se desenvolve entre as partes - ou seja, de que a relação de pesquisa é um processo social e de que esta característica deve ser submetida a um escrutínio por parte de ambas as partes envolvidas. Por outro lado, vale destacar que o fato de as respostas de os interlocutores em campo serem ou não positivas não guarda nenhuma relação com o julgamento do produto da pesquisa enquanto mais correta ou fiel à realidade que busca retratar. Mais do que restituir uma verdade, o processo dialógico da produção de conhecimento em Antropologia envolve o embate entre diferentes olhares e diferentes formações éticas. O caso das pesquisas com grupos militantes aqui discutidas constitui um exemplo de existência de acordo ético entre os pesquisadores e seus interlocutores, o que resultou em uma maior aceitação dos filmes quando finalizados. A presença de certo acordo ético é o que parece, ao final desses processos sociais, fundamentar a maior aceitação dos interlocutores acerca dos produtos das pesquisas etnográficas de que fazem parte.

\section{Notas}

1 Agradeço aos alunos das disciplinas citadas neste artigo por seu trabalho e por sua participação, que tornaram possível a presente discussão, e aos pareceristas anônimos da Ilha Revista de Antropologia, que colaboraram decisivamente na diminuição das limitações deste texto.

2 Apesar de tais situações serem cada vez menos incomuns, como é o caso dos interlocutores da pesquisa de doutorado de Gilberto Velho, que, fazendo parte do mesmo grupo social do antropólogo e sendo mesmo seus amigos pessoais, teceram comentários e críticas em relação a seus textos. Também a pesquisa de Nicolas Flamant (2005, p. 143) com executivos de uma empresa aeroespacial francesa se deu em um contexto de permanente discussão entre o etnólogo e seus sujeitos, que, segundo o pesquisador, "[...] dispunham de um capital cultural e intelectual elevado [...]" e discordavam frequentemente de suas interpretações.

3 O conteúdo desta disciplina gerou um livro introdutório, prestes a ser publicado (Guérios, no prelo).

4 A organização destas disciplinas exigiu um esforço prévio de obtenção de recursos para a aquisição de equipamentos completos de filmagem, o que foi possibilitado pelo aceite de três projetos consecutivos em editais internos de fomento à pesquisa. 
Foram assim adquiridos nove equipamentos completos de filmagem, com câmera, gravador de áudio, microfone, vara e estações gráficas de edição.

5 A exceção ocorreu com um filme acerca dos envolvidos com o universo do cosplay (pessoas que se vestem como personagens de filmes de ficção ou animes) em Curitiba. Os organizadores dos principais eventos da área na cidade não quiseram participar dos filmes porque, ocupando cargos tidos como de prestígio, como o de procurador, advogado ou médico, não gostariam de associar sua imagem com um universo visto por alguns como infantilizado.

6 O termo "etnodocumentário" é utilizado em alternância com o termo "filme etnográfico" ao longo do projeto apresentado pela equipe, o que indica que para seus membros haveria uma equivalência entre ambos.

7 Ver nota 2.

8 Para um exemplo de diferentes processos de negociação em campo segundo as especificidades das demandas dos interlocutores ao pesquisador, ver Hikiji (2009).

\section{Referências}

ASAD, T. (ed.) Anthropology \& the Colonial Encounter. London: Ithaca Press, 1973.

BARBASH, I.; TAYLOR, L. Cross-Cultural Filmmaking: a Handbook for Making Documentary and Ethnographic Films and Videos. Berkeley: Un of California Press, 1997.

CLIFFORD, J.; MARCUS, G. (Ed.). Writing Culture: the Poetics and Politics of Ethnography. Berkeley: University of California Press, 1986.

FABIAN, J. Dilemmas of critical anthropology. In: Time and the work of Antropology: critical essays 1971-1991. Chur: Harwood, 1991. p. 245-264.

FLAMANT, N. Observer, analyser, restituer. Conditions et contradictions de l'enquête ethnologique en entreprise. Terrain, Paris, v. 44, p. 137-152, 2005.

GONÇALVES, M. A. O real imaginado: etnografia, cinema e surrealismo em Jean Rouch. Rio de Janeiro: Topbooks, 2008.

GRIMSHAW, A. The Ethnographer's Eye: ways of seeing in anthropology. New York: Cambridge University Press, 2001.

GUÉRIOS, P. R. Práticas do filme etnográfico. Curitiba: Editora da UFPR. (no prelo)

HIKIJI, R. S. Imagens que afetam: filmes da quebrada e o filme da antropóloga. In: GONÇALVES, M. A.; HEAD, S. (ORG.). Devires imagéticos: a etnografia, o outro e suas imagens. Rio de Janeiro: 7 Letras, 2009. p. 115-135. 
MAGNANI, J. Discurso e representação, ou de como os Baloma de Kiriwina podem reencarnar-se nas atuais pesquisas. In: CARDOSO, R. (Org.). A aventura antropológica. São Paulo: Paz e Terra, 1986. p. 127-140.

OLIVEIRA, J. P. Etnografia enquanto compartilhamento e comunicação: desafios atuais às representações coloniais da antropologia. In: BIANCO, B. (Org. ). Desafios da Antropologia Brasileira. Brasília, DF: ABA, 2013. p. 47-74.

ROUCH, J. The camera and man. In: FELD, S. (Ed.). Ciné-Ethnography. Minneapolis: Un. Of Minnesota Press, 2003a. p. 29-46.

ROUCH, J. On the Vicissitudes of the Self: the Possessed Dancer, the Magician, the Sorcerer, the Filmmaker, and the Ethnographer. In: FELD, S. (Ed.). Ciné-Ethnography. Minneapolis: Un. Of Minnesota Press, 2003b. p. 87-101.

ROUCH, J.; TAYLOR, L. A life in the edge of film and anthropology. In: FELD, S. (Ed.). Ciné-Ethnography. Minneapolis: Un. Of Minnesota Press, 2003. p. 129-147.

VIVEIROS DE CASTRO, E. O nativo relativo. Mana, Rio de Janeiro, v. 8, n. 1, p. 113-148, 2002.

Recebido em 13/08/2014

Aceito em 05/03/2015 